\title{
Exploring the conduct of everyday life
}

\section{Manolis Dafermos}

University of Crete, School of Social Sciences, Department Psychology, Gallos University Campus, 74100-Rethymno, Crete, Greece

The book "Psychology and the Conduct of Everyday Life" edited by Ernst Schraube and Charlotte Højholt is an outstanding collection of original contributions addressing the question of how psychology can conceptualize human agency and people as active participants in social practice.

The book has 15 chapters presenting various theoretical and empirical explorations in everyday life. The theoretical and methodological ideas developed in the chapters of this book may inspire not only psychologists but more broadly scholars from various disciplines such as social anthropology, history, sociology, philosophy, and interdisciplinary fields such as cultural studies.

This book may be considered from the perspective of the strategies that have been developed as attempts to deal with the crisis in social psychology in the late 1960 s to early $1970[1,2]$. One of the aspects of the crisis of the dominant model of experimental research was connected with the dissatisfaction with experimental social psychology and its failing to provide a sufficient understanding of the challenges faced by people in their real life. The inevitable question that arose in the context of the "crisis of relevance" of dominant experimental psychology was whether it is possible to develop a theory and methodology of research that takes into account people's lives and the complexity of the social world around them.

In contrast to American experimental social psychology, in European psychology and philosophy, there are various theoretical traditions and approaches for conceptualizing real life experience of people: Dilthey's descriptive psychology, phenomenological theory, Lefebvre's critique of everyday life, Holzkamp's psychology from the standpoint of the subject, Subject-oriented sociology, discursive psychology, etc. Despite the differences in the theoretical background between previously mentioned theoretical traditions, the adherents of these theories critically distanced themselves from established view of individuals "as merely a dependent variable of the "societal structure"..." (in volume, p. 70).

The concept of conduct of everyday life offers an original perspective in which to turn from functionalism and reductionism of mainstream, "traditional" psychology - that tends to be focused on the study of isolated psychological functions - to developing an integrative view of human subjectivity and intricacy of social life and illuminating the complex interrelation between subjects and the social world.

The concept of the conduct of everyday life is based on the assumption that social scientists should be sensitive to complex social problems and multiple challenges facing people in different parts of the globe. The book presents an account of various explorations of the news ways of everyday life emerging under the influence of increasing social challenges such as economic crisis, debt, social conflicts, the new forms of labour, the increasing individualization of social life, the digitalization of the learning environment, etc.

One of the most important theoretical challenges of the concept of the conduct of everyday life is connected with the need to conceptualize social structure/agency relationship in a dialectical

\section{Publication History:}

Received: September 16, 2016

Accepted: December 01, 2016

Published: December 03, 2016

\section{Keywords:}

Psychology, Vygotsky's concept, Everyday life

way and avoid dualistic oppositions. Ole Dreier suggests a threedimensional strategy of analyzing "...the structure of society, the arrangement of everyday social practice, and the everyday conduct of life, as well as how the three are linked in practice" (in volume, p.76-77).

From this perspective, it will be intriguing to rethink the concept of the conduct of everyday life in the light of Vygotsky's concept of perezhivanie. In contrast to the separation between human action on the one hand and culture on the other, Vygotsky's concept of "perezhivanie" is based on the unity between social environment and personality: "in perezhivanie we are always dealing with an indivisible unity of personal characteristics and situational characteristics, which are represented in the perezhivanie [3]. This approach goes beyond the view of the social environment as something external in relation to personality and highlights the complex dialectical relations between social and personal as they are historically developed within social practice.

The concept of the conduct of everyday life is used in the book as a critique of everyday life rather than as its simple empirical description. Moreover, it has been included as one of the basic concepts in the theoretical framework of critical psychology for the reflection of contradictory processes of reproducing and changing social conditions of life by the concrete subjects. Anticipating the future is an essential for participating in the changing of social conditions as well as the conduct of everyday life of people. As Frigga Haug notes "...the conduct of life project would not only be something descriptively formulated in retrospect, but a hope, a utopia, which we want to become reality from the outset" (in volume, p.239). Imagining the future constitutes a way to resist the dogma that there is no alternative and encourage subjects to become active participants in changing social conditions of their own life.

Ute Osterkamp highlights that psychology from the standpoint of the subject, is not sufficient to call into questions restrictive conditions

"Corresponding Author: Prof. Manolis Dafermos, University of Crete, School of Social Sciences, Department Psychology, Gallos University Campus, 74100 Rethymno, Crete, Greece; E-mail:mdafermo@uoc.gr

Citation: Dafermos M (2016) Exploring the conduct of everyday life. Int J Psychol Behav Anal 2: 120. doi: https://doi.org/10.15344/2455-3867/2016/120

Copyright: @ 2016 Dafermos. This is an open-access article distributed under the terms of the Creative Commons Attribution License, which permits unrestricted use, distribution, and reproduction in any medium, provided the original author and source are credited. 
and examine people only as victims of oppression. It is argued that "... the conditions of our life instead of being determined by them" (in volume, p.169).

The book addresses significant and missed questions on the theory and methodology of the research of practices of everyday life and opens up new perspectives in the study of dilemmas, conflicts and contradictions faced by people in a changing social world. By critically exploring new ways of everyday living in a contemporary social world that is full of inequalities and contradictions, the book expands the discussion of the perspectives of development of critical social science.

\section{Rerefences}

1. Dafermos M. (2015) Rethinking the Crisis in Social Psychology: A Dialectical Perspective. Social Person Psy Compass 9: 394-405.

2. Faye $C$ (2012) American social psychology: Examining the contours of the 1970s crisis. Stud Hist Philos Biol Biomed Sci 43: 514-521.

3. Vygotsky LS (1994) The problem of the environment. In Valsiner J \& Van der Veer R (Eds.), The Vygotsky reader (347 - 348) Blackwell. 